\title{
The Dissertation Marathon
}

\author{
Ronald Black, Ed.D., University of Phoenix, USA
}

\begin{abstract}
We all think of a marathon as a long-distance running event with an official distance of 42.195 kilometers (26 miles and 385 yards). Throughout time marathon runners have pursued their longest goals by allowing their body to adapt to the new stresses through training. Training for a marathon takes intense preparation, dedication and skill. It is imperative not to allow day to day decisions to counteract the hard work and planning of the final stages of the marathon. A few basic guidelines can minimize the challenges of the journey and make the marathon experience exciting and pleasant for the runner.
\end{abstract}

Students pursuing the doctorate degree face the same challenges as the marathon runner. Training for the dissertation process is not unlike training for a marathon. It requires intense preparation, dedication and skill. In many ways, conducting doctoral research and writing the dissertation is like running a marathon, enduring hills and valleys, mountains, rivers and frantic road blocks along the way. It is a long and weary race but in the successful end will lead to the final race in the doctoral journey; defending and publishing the dissertation.

This paper will serve as a performance-based goal-driven roadmap that will guide the doctoral dissertation candidate through each mile of the dissertation marathon, with clear benchmarks to minimize the challenges of the journey to cross the finish line and graduate.

Keywords: Dissertation Marathon; Doctoral Dissertation Roadmap; Doctorate Degree

\section{THE DISSERTATION MYSTERY}

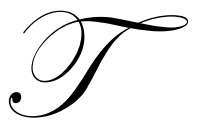

hroughout time marathon runners have pursued their longest goals by allowing their body to adapt to the stress that is built up when considering running a marathon. The marathon of today is a longdistance running event with an official distance of 42.195 kilometers (26 miles plus 385 yards). Hal Higdon (1999) points out in Marathon: The Ultimate Training Guide "Even thinking about running that far takes a certain amount of endurance" (p. 21). Higdon notes that running a 26 mile marathon is a stressful activity. The stress can become extreme if runners do not slow down, drink plenty of fluids, and focus on the finish line.

Students pursuing the doctorate degree face the same challenges as the marathon runner. Training for the dissertation process is not unlike training for a marathon. It requires intense preparation, dedication and skill. Today's colleges and universities challenge doctoral learners to become creative scholars and problem solvers throughout the doctorate program courses and into the final step, writing and defending the dissertation. Unlike doctoral courses that are presented in short and structured time frames fitting within a quarter or semester, the dissertation is the first large project where the learner will apply the knowledge acquired in the doctoral courses to address a research problem, analyze research results, and present the results in a clear and concise technical document. In many ways, conducting doctoral research and writing the dissertation is like running a marathon, enduring hills and valleys, mountains, rivers and frantic road blocks along the way. It is a long and weary process but in the end will lead to the final race in the doctoral journey; defending the dissertation and becoming a $\boldsymbol{D r}$.

The main contrast between running a marathon and writing a dissertation is that they both require an extreme amount of energy. In both situations, the marathon runner and dissertation writer can't go all out at the beginning because they might not have the strength to make it through at the end. Marathon runners and dissertation writers must take every step carefully and slowly because every step, no matter how slow, will bring the finish line 
closer. Like a marathon, writing the dissertation requires perseverance. Although a marathon is usually run on a specific day, writing a dissertation cannot be accomplished in a day. This is why it is essential to condition the body and mind to endure. Working on the dissertation a little at a time conditions the body and mind to persevere even if it becomes tired and not in the mood. The candidate may get frustrated while writing each chapter but as the light at the end of the tunnel becomes brighter, the candidate will become refreshed and want to continue.

\section{PLANNING THE DISSERTATION MARATHON}

The classic long-distance race can expose nerve endings, and bring you closer to recognizing the real you (Higdon, (1999). Like the long-distance race, writing a dissertation will do the same. Both require a great deal of patience, diligence, and a step-by-step plan. Just as the runner who has failed to plan for the long-distance race will end up on the sidelines, the doctoral candidate who starts writing without a plan will end with the title All But Dissertation (ABD).

Long-distance marathon training usually starts with rest, then easy short runs, and finally long runs beginning with 10 miles then leading up to 26 miles. There are a number of alternative training that the marathon runner my do to stay in shape. These including walking 30-60 minutes each day, solid cross-training such as swimming, strength-training, bicycling, yoga or another effort. The key is not to become excessively tired during training to build the stamina for the long-distance race.

Like marathon training, the first week of dissertation writing begins slowly and gains momentum as the dissertation writing proceeds. During this period the dissertation writer begins by concentrating on the dissertation topic. Choosing a dissertation topic poses a major obstacle for many doctoral learners. Choosing the right dissertation topic is crucial. The topic establishes the dissertation roadmap and will become identified with the dissertation writer during doctoral study, at graduation, and beyond. The dissertation topic is not going to come while reading articles, journals or books but will come in the middle of the night when you wake up and say " $\boldsymbol{A h}$ ha...."

During the early weeks of dissertation writing, the dissertation writer will come up with the topic that is $\boldsymbol{R I G H T}$ for the research by answering the following questions:

- $\quad$ Is the topic appropriate to my degree?

- Is the topic of general interest to me and my dissertation advisor?

- $\quad$ Am I passionate about this topic?

- Does the topic address a real problem or question?

- Is the topic appropriate for the subjects I have available to work with?

- Is the topic narrow enough to be manageable?

- Is this topic doable, given my time frame, resources, and availability of data sources?

- $\quad$ Is the topic within my range of competence?

- $\quad$ Does it satisfy my gut feelings?

(http://www.dissertationdoctor.com/advice/topic.html)

Doctoral dissertations should be original, researchable, and contributory to the field. Madsen (1992) states in Successful Dissertations and Theses, "A topic must have the potential to do at least one of the following:

- uncover new facts or principles,

- $\quad$ suggest relationships that were previously unrecognized,

- challenge existing truths or assumptions,

- afford new insights into little-understood phenomena or suggest new interpretations of known facts that can alter people's perceptions of the world around them. (p. 38).

There are very little rules in selecting a topic. Many universities require the dissertation topic to be focused on the candidate's doctoral program. The main criterion is the dissertation topic shows that the doctoral candidate 
can conduct acceptable research. Selecting the topic is one of the most important decisions the candidate will make in the doctoral dissertation journey. Once a topic is selected, the doctoral candidate will then put together their dissertation committee.

\section{THE MARATHON TEAM}

Team work is key when preparing for a long-distance marathon and writing the dissertation. The longdistance marathon team helps prepare for the race and will be there to cheer. In most cases, the team is family, friends and colleagues. When writing the dissertation both academic and scholarly direction as well as personal direction is needed. Family, colleagues and friends will guide and provide motivation as the dissertation is written. Academic and scholarly direction is provided by the dissertation committee. The university dissertation guidelines will dictate the make-up of your committee. Selecting a dissertation committee is one of the most important decisions that a doctoral candidate will make during their dissertation journey. It may look like an easy and straight forward task but there are often complications and issues that may come up during the process. It may look like an easy and straight forward task but there are often complications and issues that may come up during the process.

At most institutions the dissertation committee is made up of three faculty members, one will be your dissertation advisor/chair and two will be committee members. The dissertation committee becomes your "doctoral family" while writing the dissertation. The candidate must begin searching for a dissertation committee early in the program. The candidate should research faculty while taking program content courses. Getting to know the faculty's interests and research pursuits is a way to insure that there is a fit with your dissertation topic. Collaborating with the faculty early will help make good decisions as the dissertation approaches but caution is required. Concentrating on one faculty member may not be the best approach. Continue to explore all options, talk to as many faculty members as possible. Searching for a dissertation chair is like going on a blind date. During that date you want to find out all you can about your date to see if you are compatible. The candidate and chair will be together for a long time. Explore all options and interview each potential faculty member carefully. Interview all possible candidates for the dissertation committee. In the interview let the potential committee member know that you are interested to learn more about them. The interview questions should center around the type of research the faculty member has worked with, the number of dissertation committees that the faculty member is currently on and how many have they been on where the candidate graduated, what is their working style, how often they will review your work, what specific requirements do they have, and what is their availability for in-person and telephone meetings. The questions could be:

- Do you specialize in any particular type of research?

- What was your dissertation methodology, design, topic? Was your dissertation published?

- $\quad$ How long do you typically take to provide feedback on drafts?

- $\quad$ How many drafts are you willing to read? Is there a maximum number of drafts you will read?

- What is the primary focus of your feedback — dissertation structure and content, method, research, writing style, etc.?

- $\quad$ Do you prefer to serve on committees with particular faculty members?

- $\quad$ Are you comfortable having a member of the committee from outside the university?

- $\quad$ Are you willing to communicate in person and via telephone?

- $\quad$ Are you planning any sabbaticals or lengthy vacations?

- In general, what are your expectations of a doctoral dissertation candidate?

Like dating, the key to selecting a dissertation committee is to be honest and straight forward letting the potential committee member know your expectations of them. When selecting a committee, the most important thing that everyone must understand is that this is your dissertation, not theirs. You need to closely watch out for yourself and ensure you will receive the needed advice to complete your dissertation and graduate. The best way to do this is to create and agree on a dissertation agreement. I call this agreement the dissertation pre-nuptial agreement. This agreement may focus on the following key points: 


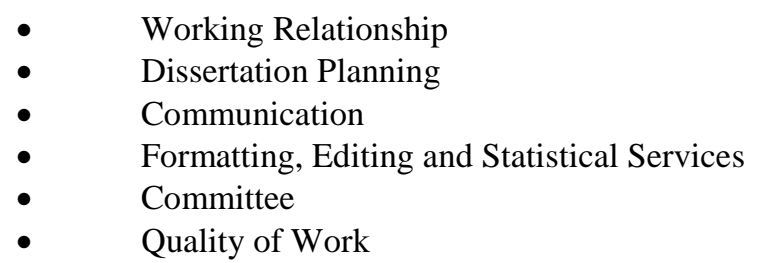

Both the doctoral candidate and the chair should sign and date the agreement. Of course, like a marriage, disagreements and changes may come up but both the candidate and chair must understand the most important person on the dissertation committee is the candidate. The dissertation chair provides direct advice and support as the dissertation is written. The committee member reviews completed chapters and provide feedback. This relationship may be thought as a marriage, where trust and communication become the main goal of the relationship. The dissertation chair guides the marathon, helping the candidate to the finish line.

\section{THE FIRST 10 MILES}

In a marathon, the runner arrives at the start with plenty of time to spare to avoid missing the start. Once at the start, the runner will check out the groups lining up to line up with a group that will run at the same pace. The runner will be sure not to line up with runners who will run at their pace. Running faster at the start will push the early pace faster than you are comfortable with which may be disastrous in the end.

Once the starting gun goes off, the fun begins. For the first few miles the runner will run at a slow and steady pace building speed and moving forward. The race becomes surprisingly easy as each mile is reached.. Soon the runner moves ahead, slowly putting down the hammer gaining speed and stamina to approach the half-way point.

The early stage of the dissertation marathon begins with a plan worked out by the doctoral candidate and the dissertation plan. This plan will guide the candidate through the process as each chapter is written, the study is conducted, and the dissertation is submitted for review, and graduation. The purpose of dissertation plan is to clearly outline what activities must be accomplished by the dissertation student, Chair, and committee members for a candidate to complete the dissertation. Once completed, this project plan will serve as a contract between the student, Chair and committee members. Any changes to this plan must be approved by all parties.

Now that the plan is complete and agreed upon the dissertation starting gun goes off...and the fun begins... The first few miles of the dissertation journey focus on the research problem and how it aligns to the dissertation topic approved by the chair. Coming up with the problem takes considerable thought and research. The problem statement is the most critical element of the doctoral dissertation. According to Simon (2011) the problem statement is the heart of a doctoral dissertation and where you need to begin. The problem statement explains the rationale for the research, validates its importance, determines the research design, and ensures reliability. After reading the problem statement, the reader will know why you are doing this study and be convinced of its importance. In their article, Strategies To Win: Six-Steps For Creating Problem Statements In Doctoral Research (2005), Drs. Kimberly Blum \& Amy Preiss stress,

- Writing a problem statement can be compared to a professional racecar driver strategically reducing speed before going around a steep turn. Slowing down increases the driver's ability to control the car and defeat drivers who accelerated too quickly and lost control of the car. Slowing down initially enables the driver to win the race. Students writing a problem statement should implement a similar strategy. Students should take time to consider what constitutes a viable problem before writing the problem statement. Doctoral learners should slow down, consider the problem to explore and devise a strategic plan. If students invest this time initially, they will experience less difficulty in completing the remaining parts of the proposal.

Creating problem statements can be challenging and time consuming but because the problem statement drives the purpose of the study, the choice of research design, and the resulting conclusions, writing an effective problem statement is critical to the success of the dissertation. 
Continuing the dissertation marathon, the candidate is now ready to focus on the purpose of the study. The purpose statement is the study intent, which is the objective the study is designed to achieve. The process of developing the purpose statement provides an opportunity for the researcher to reflect on the overall scope and focus of the project and anticipate issues that may arise. The purpose statement must be reflective of and aligned with the problem statement. The purpose statement defines the reason for the research or the research goals. The purpose statement begins by identifying the research methodology and design followed by how the variables will be analyzed. The purpose statement is succinct and to the point directly aligned with the problem.

The next mile focuses on determining the research questions to be answered in the study. A well-stated research question drives the investigation and implementation of the study. Dissertation research defines the questions that the results of the study will be used to answer and should be phrased in a way that will produce observable and measurable answers. Research questions guide the inquiry of the research by narrowing and focusing the purpose statement. They define the questions that the results of the study will be used to answer and should be phrased in a way that will produce observable and measurable answers. Typically, a problem statement will have one or two research questions associated with it. In quantitative studies, these research questions are most often descriptive, correlational, or experimental. In qualitative studies, the research questions are generally broad in nature. To be effective, a research question must be manageable and contain appropriate restriction, qualification, and delineation. The formulation of research questions must be aligned with the selection of the research method and design that will be used to generate the data for the study. The analysis of these data will provide the answers to the research questions.

Now that the foundation of the dissertation has been established the dissertation runner picks up speed heading for the half-way point; completing the dissertation proposal. Using the topic, problem, purpose and research questions, chapter 1 may be completed by adding sections to support the problem. At the first-quarter point, the candidate now begins the literature review.

The literature review serves an important purpose in the dissertation. It supports the importance and timeliness of the dissertation topic and problem. The literature review is extensive in a dissertation proposal, and it is often the largest section.

According to Cooper (1988)... a literature review uses as its database reports of primary or original scholarship, and does not report new primary scholarship itself. The primary reports used in the literature may be verbal, but in the vast majority of cases reports are written documents. The types of scholarship may be empirical, theoretical, critical/analytic, or methodological in nature. Second a literature review seeks to describe, summarize, evaluate, clarify and/or integrate the content of primary reports.

Moving on at a steady pace the candidate now focuses on how the study will be conducted. Chapter 3 includes a discussion of the research methodology for the study. The chapter begins with a detailed discussion of the appropriateness of the method, the design, and how the chosen method and design will help accomplish the study goals. Following a discussion of the study population, chapter 3 includes a discussion of the processes for collecting and analyzing data. The chapter concludes with a discussion of instrumentation, instrumentation reliability, and issues associated with the internal and external validity of the study.

With the dissertation proposal complete, the candidate is at the Half-Way Point... The next step is to add the front matter and back matter and submit to the dissertation for a quality review. Front matter may include:

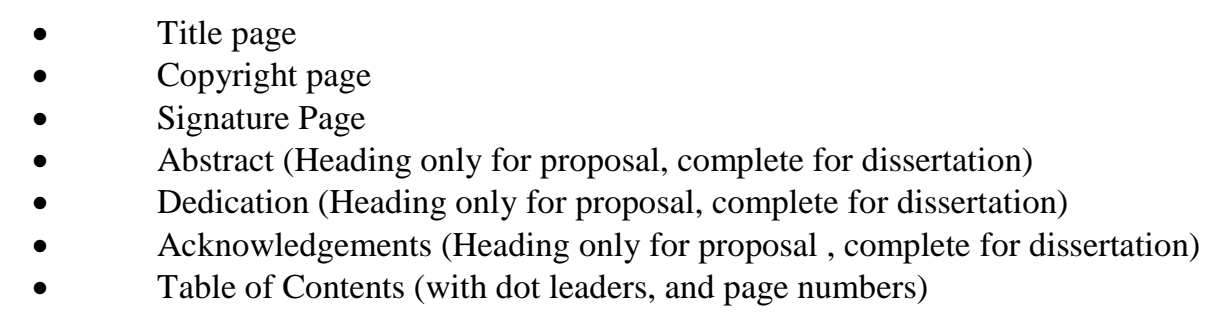


- $\quad$ List of Tables (if more than 1 table included)

- $\quad$ List of Figures (if more than 1 figure is included

Back matter is optional but almost always is used when additional material is needed to support he dissertation.

At this point the dissertation runner may take a breath, take a short break and prepare to collect data. Prior to collecting data an application is normally required to submit to the Institutional Review Board to insure that the study is ethical and will not violate any of the subjects rights. With both dissertation committee and IRB approval the runner may proceed at a rapid pace toward the finish line.

\section{STRIVING TO FINISH}

The last half of a long-distance marathon can make or break the runner, especially the last 3 miles. . Running the correct pace is crucial in the marathon, especially for the first time runner. Not all runners who begin the race finish the race. Many drop out prior to the finish line. The strategy is to run steadily faster from miles 13 to 20 and then pick up the pace during the final miles when you know you can finish. Pacing will get the runner to the finish line.

Pacing is also key at this stage of the dissertation marathon. Now that the dissertation runner has completed data collection and analysis the next steps are to write chapters 4 and 5. Chapter 4 is fairly easy to write since it basically reports the results of the study without an explanation of what they mean. The purpose of Chapter 4 is to report, in appropriate detail, the results produced by the completion of the systematic and careful application of the analytical research techniques to the data. No statement should be made in the chapter that is not directly supported by the results of the data analysis.

In a brief introduction, the researcher will state the key features of and reasons for the data collection and data analysis techniques employed. In the body of the chapter, the writer reports the results and findings generated by the analyses of data without editorial comment.

This chapter includes solely the analysis of data, the testing of hypotheses, and/or the careful dissection of research questions, introducing no interpretation of findings. The results of testing each statistical hypothesis must be clearly presented and without editorial comment. Significance of results and findings must be stated clearly, with appropriate qualifications and constraints. Tables and graphs can be used and are illustrative of the verbal presentation of data. Graphical representations do not take the place of a narrative, but they clarify the verbal presentation. The chapter ends with a summary of the key points covered in the chapter and transitions smoothly to chapter 5.

As the dissertation runner moves swiftly to the finish line, chapter 5 concludes the research study, providing insightful conclusions into the implications of the inquiry for various constituents and the recommendations, supported and justified, emerging from the analyses and findings. This chapter includes the researcher's conclusions and recommendations. Following an introduction to the chapter the conclusions are presented based on the literature review and the analysis of data. The candidate will introduce discussions that highlight the importance, significance, and meaning of the inquiry to constituents such as managers, employers, employees, researchers, communities, government agencies, business leaders, and others.

The candidate should clearly indicate how the conducted study is significant, substantial, and contributory to the related body of knowledge. This section should also describe the extent to which scholars and/or practitioners will be able to incorporate the study into their behavior. The conclusions should answer the questions: So what? and Who cares?

As the dissertation runner nears the final mile, recommendations are written. The writer indicates the recommendations how the results of the study should be addressed in a positive way focusing on constituencies and the broader society. The ethical dimensions of the research are discussed and suggestions for further research are described and supported. The candidate will end the dissertation by summarizing chapter 5 in a brief paragraph. 
Front matter is now updated by adding the abstract, dedication, acknowledgements and updating the table of contents. Back matter is added to support the findings and conclusions. The dissertation is now sent to the dissertation committee for final approval.

\section{CROSSING THE FINISH LINE}

As hundreds of Marathon runners cross the finish line, they pant and limp, unsure where to direct their next wobbly steps. They had run 26.2 miles. Some runners cry and collapse on a nearby sidewalk, while others pump their fists in their air. After crossing the finish line, the marathon runner is reunited with friends and family, where they were invited to cool down and bask in their accomplishments.

Approaching the finish line the dissertation runner meets the dissertation defense. Most universities require a formal defense of the dissertation before the chair and committee sign a candidate's dissertation. In order to defend his or her dissertation successfully, the candidate must demonstrate competence in describing, discussing, and supporting all aspects of the study to the committee and, potentially, to a broad academic audience. The oral defense is conducted very differently at many institutions. Some are in person, some via Internet video, and others via teleconference. The candidate is responsible for presenting the methods and findings of the dissertation study, typically in a Microsoft PowerPoint slideshow or some other graphical format. Depending on the method used, advanced copies of the defense materials should be provided to the dissertation committee. The candidate should be prepared to respond to all committee questions concerning the dissertation during and following the presentation. Candidates must demonstrate a comprehensive understanding of their study and the context in which it exists in order to complete the defense successfully. Failure to demonstrate this level of understanding may result in additional work required by the committee, potentially extending the time required to complete the dissertation. A successful defense will end with a signed dissertation and moving to graduation.

Crossing the finish line adds a sigh of relief, free to begin life again. The doctoral program is complete from courses to the dissertation. The student can now remove the title "candidate" indicating that the final title is now $\mathrm{Dr}$. Like the marathon runner crossing the finish line, smiles indicate success. Now for the trophy! Marathon trophies come in all shapes and sizes, the most common being the gold, silver and bronze medal on a colored ribbon to indicate first, second and third place. For the dissertation runner, the trophy includes the doctoral diploma, doctoral regalia and the doctoral hood. With the faculty and staff sitting and cheering in the audience at commencement the President of the university confers the doctorate degree. As the new $\boldsymbol{D r}$. crosses the stage, the dissertation chair will be there to "hood" the new graduate with a colorful doctoral hood representing completion of the doctorate. An academic hood is the doctoral trophy, worn draped around the neck and over the shoulders, displayed down the back. The hood's length signifies the doctoral degree level; with the institution's colors in the lining and a velvet trim in a standardized color that signifies the scholar's field. The doctoral journey is now over and the new $\boldsymbol{D r}$. may now bask in their accomplishments, remembering:

It's not where you start it's where you finish.

It's not how you go, it's how you land.

A hundred-to-one shot, they called him a klutz,

He can outrun the favor all he needs is the guts.

"Your final return will not diminish

And you can be the cream of the crop.

It's not where you start it's where you finish

And you're gonna finish on top."

"It's Not Where You Start (It's Where You Finish)" Lyrics by Dorothy Fields

\section{ACKNOWLEDGEMENTS}

Concept credited to: Summer Huntley-Dale, RN, MS, Assistant Professor, Western Carolina University, School of Nursing, Ph.D. student, University of Phoenix, School of Advanced Studies. 


\section{AUTHOR INFORMATION}

Dr. Ronald (Ron) Black, In his role as a Full-Time Academic Faculty member for the University of Phoenix, School of Advanced Studies, Ron provides instructional support for the Ph.D. Higher Education Administration and Ed.D Educational Technology programs. He is a dissertation chair and serves on dissertation committees. Ron facilitates Doctoral Residency courses, Doctoral Leadership courses, Doctoral Business courses, Doctoral Education courses, Doctoral Information Systems \& Technology courses, Doctoral Research and PHD in Higher Education Administration courses. Dr. Black has served as a faculty member and vice president at five institutions of higher learning over the past thirty years. He has also conducted considerable research studies in educational leadership, technology and distance learning. Ron is an author of articles on education, technology and strategic business alliances with speaking engagements at national and International conferences including Oxford University and the United Nations. Ron earned his BS in Secondary Education and his Masters in Education from Rhode Island College and an Ed.D. from Nova Southeastern University. E-mail: Ronald.Black@phoenix.edu.

\section{REFERENCES}

1. Black, R., Conrad, K. and Blum, K. (2009). The Mentor Handbook, University of Phoenix Online, School of Advanced Studies.

2. Blum, K. and Preiss, A. (2005). Strategies To Win: Six-Steps For Creating Problem Statements In Doctoral Research. University of Phoenix Online, School of Advanced Studies.

3. Clancy, C. (2010). Clancy's quotes. Retrieved from http://clancycross.wordpress.com/2008/08/31/thefinish-line/.

4. Highdon, H. (199). Marathon, the ultimate training guide. New York, NY: St. Martin's Press.

5. Madson, D. (1992). Successful Dissertations and Theses. San Francisco, CA: Jose-Bass Publications.

6. Roberts, C. M. (2004). The Dissertation Journey. Thousand Oaks, CA: Sage Publications.

7. Simon, M. K. (2011). Dissertation \& scholarly research, recipes for success. San Diego, CA: Dissertation Success, LLC. 